\title{
Myoclonus and Recurrent Cardioinhibitory Vasovagal Syncope after Abdominal Surgery in a Critical Care Setting
}

\author{
Ana Belén Fernández*, Elena Martín, Ramsés Marrero, David Viera \\ Department of Anesthesiology and Postsurgical Intensive Care Unit, Ntra Sra De Candelaria University Hospital, Santa Cruz de \\ Tenerife, Spain \\ Email:*anabfp@gmail.com
}

How to cite this paper: Fernández, A.B., Martín, E., Marrero, R. and Viera, D. (2020) Myoclonus and Recurrent Cardioinhibitory Vasovagal Syncope after Abdominal Surgery in a Critical Care Setting. World Journal of Cardiovascular Diseases, 10, 274-277. https://doi.org/10.4236/wjcd.2020.105025

Received: December 31, 2019

Accepted: May 5, 2020

Published: May 8, 2020

Copyright $\odot 2020$ by author(s) and Scientific Research Publishing Inc. This work is licensed under the Creative Commons Attribution International License (CC BY 4.0).

http://creativecommons.org/licenses/by/4.0/

\section{Keywords}

Vasovagal Reflex, Syncope, Cardioinhibitory Response, Autonomic Failure, Asystole

\section{Letter to the Editor}

Syncope is defined as transient loss of consciousness (TLOC) due to global cerebral hypoperfusion, with a rapid onset, short duration, and spontaneous complete recovery. Syncope shares many clinical features with other disorders, which therefore feature in one another's differential diagnosis. This group of disorders is labelled TLOC. TLOC is defined as a state of real or apparent LOC with loss of awareness, characterized by amnesia for the period of unconsciousness, abnormal motor control, loss of responsiveness, and short duration.

Vasovagal reflex is the most common cause of syncope in any setting and age group accounting for $21 \%$ of all incidents. Many patients have recurring episodes and a few have major trauma following vasovagal syncope (VVS) [1].

The etiology of reflex syncope (neurally mediated) can be divided into its common form (vasovagal, where postural challenge: standing and less common sitting, or emotion causes the abnormal reflex) and the situational syncope (where this reaction is used by a specific trigger: micturition, gastrointestinal stimulation: swallow, defaecation, post-exercise, and cough or sneeze). The non-classical form of reflex syncope occurs with uncertain or apparently absent triggers and/or atypical presentations. This group also encompasses syncope associated with low adenosine plasma levels [2].

${ }^{\star}$ Corresponding author. 
All forms of syncope, but mostly reflex syncope and orthostatic hypotension $(\mathrm{OH})$, are more likely to occur or are more severe when various factors are present: medication causing low Blood Pressure (BP) (due to vasodilatation or hypovolemia), alcohol use, volume depletion (haemorrhage, low fluid intake, diarrhoea, vomiting), pulmonary diseases causing reduction in brain oxygen supply, environmental factors (thermal stress) [3].

The autonomic malfunction (depending on the predominant efferent stimulus: withdrawal of sympathetic tonus y/or increased vagal tone) causing reflex syncope is either a ${ }^{*}$ Vasodepressive response: loss of sympathetic vasoconstrictive tone with resultant hypotension, ${ }^{*}$ Cardioinhibitory response: active parasympathetic stimulation with resultant bradycardia or asystole or a *Mixed response. Young patients are more prone to cardioinhibitory syncope, whereas older individuals are more likely to have a hypotensive response. Moreover, an individual patient may demonstrate different types of responses on different occasions. For example, micturition syncope and orthostatic VVS may equally well present as cardioinhibitory or as vasodepressor syncope.

Cardioinhibition has been defined by the Vasovagal Syncope International Study (VASIS) as a heart rate $(\mathrm{HR})<40$ beats per minute $(\mathrm{bpm})>10 \mathrm{~s}$ and/or asystole $>3 \mathrm{~s}[4]$.

A diurnal variation in vagal activity was demonstrated with higher vagal activity occurring at night. Clarke et al. demonstrated that a sinus bradycardia occurs at night with the lowest values seen around $04.00 \mathrm{~h}$ a.m. [5].

Pacemaker implantation is clearly indicated in patients with documented cardioinhibitory syncope in the absence of a vasodepressor component, which can compromise their quality of life [4].

Establishing a relationship between symptoms and bradycardia should be the goal of the clinical evaluation of patients with syncope and a normal baseline ECG. The efficacy of pacing depends on the clinical setting.

Recently, we experienced an interesting case of VVS at night most of time, after intestinal surgery,

A 68-year-old, 70-kg woman, was admitted in hospital for emergence laparoscopic intestinal resection, due to acute intestinal obstruction caused by adhesive band. Her personal background included hiatal hernia, arterial hypertension, paroxysmal supraventricular tachycardia, diverticular disease, inguinal hernia repair and total hysterectomy by uterine prolapse. Normal preoperative electrocardiogram (ECG). Usual medications: Bisoprolol $2.5 \mathrm{mg} / \mathrm{d}$, Irbesartan 75 $\mathrm{mg} / \mathrm{d}$. Non-smoker patient.

On the 6th post-surgical day, the patient developed a brief myoclonic jerk in arms after loss of consciousness and extreme bradycardia (20 bpm) in supine position. $1 \mathrm{mg}$ atropine was administered. Her neurological exploration showed dysarthria for a few seconds. Blood pressure was $108 / 74 \mathrm{mmHg}$, heart rate was 58 beats/min, and temperature was $36.1^{\circ} \mathrm{C}$. The patient referred abdominal pain and a sudden onset palpitation immediately before LOC. 
Point-of-care glucose, basic biochemistry, creatine kinase, troponin, haemogas analysis/oxygen saturation and complete blood count with differential returned within normal range. 12-leads electrocardiogram (ECG) revealed sinus bradycardia, without A-V block. Cranial CT scan, electroencephalogram and echocardiography were normal. No previous episodes of orthostatic hypotension $(\mathrm{OH})$. Bisoprolol $2.5 \mathrm{mg}$ and Irbesartan $75 \mathrm{mg}$ were administered in the morning. A similar episode happened $12 \mathrm{~h}$ later, at 23:00 h p.m. Endovenous isoproterenol infusion was started $(0.2-0.5 \mathrm{~g} / \mathrm{kg} / \mathrm{min})$ and the patient was admitted to the Postsurgical Intensive Care Unit (PICU) for hemodynamic and neurologic monitoring, but within $3 \mathrm{~h}$ from arrival, a $20 \mathrm{~s}$ sinus pause accompanied by loss of consciousness was objected. Atropine and external cardiac compressions were initiated.

A transient pacemaker was implanted for 3 days, then remaining without electrocardiographic abnormalities. Holter recording: sinus rhythm 75 bpm (Max 113 - Min 52). On the 10th day, the patient was discharged at home successfully, with ramipril $2.5 \mathrm{mg} / \mathrm{d}$. Bisoprolol and Irbesartan were suspended. Six months after, her cardiological evaluation was normal.

It has been reported that discontinuation/reduction of agents that lower blood pressure, can reduce the recurrence of VVS. The SPRINT research group reported that the people targeting systolic blood pressure to $140 \mathrm{mmHg}$ show a twofold reduction of the risk of new syncopal episodes, compared to patients targeting SBP to $120 \mathrm{mmHg}$ [6].

Beta-blockers can worsen $\mathrm{OH}$ with several mechanisms including the reduction of the sympathetically-mediated increases in stroke volume, heart rate or peripheral vascular resistance. In addition, beta-blockers may worsen bradycardia in cardioinhibitory syncope. Thus their use is currently not recommended in the European guidelines.

Key in the prevention of recurrence of syncope is careful avoidance of agents that lower BP, i.e. any antihypertensive agents, nitrates, diuretics, neuroleptic antidepressants or L-dopa antagonists. The BP-lowering agents (angiotensin-converting enzyme inhibitors, angiotensin receptor blockers, and calcium-channel blockers) should be used preferentially, especially among patients at high risk of falls, as diuretics and beta-blockers are associated with $\mathrm{OH}$ and falls and should be avoided in at-risk individuals.

Cardiac asystole is known to cause clinical manifestations mimicking seizures. Focal neurological events can occasionally occur due to hypotension and syncope even in patients without significant carotid artery stenosis (so-called "hypotensive TIA"). Although these neurological events occur in only $6 \%$ of patients with recurrent syncope, their misdiagnosis is particularly important because they may lead to a lowering of BP with antihypertensive medications (e.g. if focal neurology is mistakenly attributed to vascular pathology rather than hypotension) and to a further increase of the risk of syncope and neurologic events. 
In our patient the VVS was triggered, probably by a gastrointestinal stimulation/ inflammation secondary to surgery, reflecting a parasympathetic predominance enhanced by the vasodepressor effect of irbesartan plus bisoprolol.

Gastrointestinal surgery itself (trauma, inflammation, paralytic ileus, hypotension, hypovolaemia...) can trigger VVS in selected patients, especially at night, so it's important to take into account, drugs that can contribute to autonomic dysfunction, in order to identify it, and prevent VVS.

\section{Acknowledgements}

Thanks to Drs E. Martin, R. Marrero and D. Viera for constructive criticisms.

\section{Conflicts of Interest}

The authors declare no conflicts of interest regarding the publication of this paper.

\section{References}

[1] Romano, S., Branz, L., Fondrieschi, L. and Minuz, P. (2019) Does a Therapy for Réflex Vasovagal Syncope Really Exist? High Blood Pressure \& Cardiovascular Prevention, 26, 273-281. https://doi.org/10.1007/s40292-019-00327-3

[2] da Cunha, G.J.L., Rocha, B.M.L., Gomes, R.V., Silva, B.V., Mendes, G., Morais, R., et al. (2019) A Systematic Review on Recurrent Cardioinhibitory Vasovagal Syncope: Does Pacing Therapy Break the Fall? Pacing and Clinical Electrophysiology, 42, 1400-1407. https://doi.org/10.1111/pace.13790

[3] Del Rosso, A., Ungar, A., Maggi, R., Giada, F., Petix, N.R., De Santo, T., Menozzi, C. and Brignole, M. (2008) Clinical Predictors of Cardiac Syncope at Initial Evaluation in Patients Referred Urgently to a General Hospital: The EGSYS Score. Heart, 94 1620-1626. https://doi.org/10.1136/hrt.2008.143123

[4] Clarke, J.M., Hamer, J., Shelton, J.R., Taylor, S. and Venning, G.R. (1976) The Rhythm of the Normal Human Heart. Lancet, 2, 508-512. https://doi.org/10.1016/S0140-6736(76)90801-1

[5] Brignole, M., Moya, A., de Lange, F.J., et al. (2018) 2018 ESC Guidelines for the Diagnosis and Management of Syncope. European Heart Journal, 39, 1883-1948. https://doi.org/10.1093/eurheartj/ehy037

[6] SPRINT Research Group, Wright Jr., J.T., et al. (2015) A Randomized Trial of Intensive versus Standard Blood Pressure Control. New England Journal of Medicine, 373, 2103-2116. https://doi.org/10.1056/NEJMoa1511939

[7] Ryan, D.J., Harbison, J.A., Meaney, J.F., Rice, C.P., King-Kallimanis, B. and Kenny, R.A. (2015) Syncope Causes Transient Focal Neurological Symptoms. QJM, 108, 711-718. https://doi.org/10.1093/qjmed/hcv005

[8] Canney, M., O'Connell, M.D., Murphy, C.M., O'Leary, N., Little, M.A., O'Seaghdha, C.M. and Kenny, R.A. (2016) Single Agent Antihypertensive Therapy and Orthostatic Blood Pressure Behaviour in Older Adults Using Beat-to-Beat Measurements: The Irish Longitudinal Study on Ageing. PLoS One, 11, e0146156.

https://doi.org/10.1371/journal.pone.0146156 